\title{
Nephrotoxicity of immune checkpoint inhibitors beyond tubulointerstitial nephritis: single-center experience
}

Omar Mamlouk', Umut Selamet ${ }^{2}$, Shana Machado ${ }^{1}$, Maen Abdelrahim³ ${ }^{3}$ William F. Glass ${ }^{4}$, Amanda Tchakarov ${ }^{4}$, Lillian Gaber ${ }^{5}$, Amit Lahoti ${ }^{6}$, Biruh Workeneh ${ }^{6}$, Sheldon Chen ${ }^{6}$, Jamie Lin ${ }^{6}$, Noha Abdel-Wahab ${ }^{7,8}$, Jean Tayar ${ }^{8}$, Huifang Lu ${ }^{8}$, Maria Suarez-Almazor ${ }^{8}$, Nizar Tannir ${ }^{9}$, Cassian Yee ${ }^{10}$, Adi Diab ${ }^{10 \dagger}$ and Ala Abudayyeh ${ }^{6 *}$

\begin{abstract}
Rationale \& Objective: The approved therapeutic indication for immune checkpoint inhibitors (CPIs) are rapidly expanding including treatment in the adjuvant setting, the immune related toxicities associated with CPI can limit the efficacy of these agents. The literature on the nephrotoxicity of CPI is limited. Here, we present cases of biopsy proven acute tubulointerstitial nephritis (ATIN) and glomerulonephritis (GN) induced by CPIs and discuss potential mechanisms of these adverse effects.

Study design, setting, \& participants: We retrospectively reviewed all cancer patients from 2008 to 2018 who were treated with a CPI and subsequently underwent a kidney biopsy at The University of Texas MD Anderson Cancer Center.
\end{abstract}

Results: We identified 16 cases diagnosed with advanced solid or hematologic malignancy; 12 patients were male, and the median age was 64 (range 38 to 77 years). The median time to developing acute kidney injury (AKI) from starting CPIs was 14 weeks (range 6-56 weeks). The average time from AKI diagnosis to obtaining renal biopsy was 16 days (range from 1 to 46 days). Fifteen cases occurred post anti-PD-1 based therapy. ATIN was the most common pathologic finding on biopsy (14 of 16) and presented in almost all cases as either the major microscopic finding or as a mild form of interstitial inflammation in association with other glomerular pathologies (pauci-immune glomerulonephritis, membranous glomerulonephritis, C3 glomerulonephritis, immunoglobulin A (IgA) nephropathy, or amyloid A (AA) amyloidosis). CPIs were discontinued in 15 out of 16 cases. Steroids and further immunosuppression were used in most cases as indicated for treatment of ATIN and glomerulonephritis (14 of 16), with the majority achieving complete to partial renal recovery.

Conclusions: Our data demonstrate that CPI related AKI occurs relatively late after CPI therapy. Our biopsy data demonstrate that ATIN is the most common pathological finding; however it can frequently co-occur with other glomerular pathologies, which may require immune suppressive therapy beyond corticosteroids. In the lack of predictive blood or urine biomarker, we recommend obtaining kidney biopsy for CPI related AKI.

Keywords: Checkpoint inhibitors, Immunotherapy, Glomerulonephritis, Acute tubulointerstitial nephritis

\footnotetext{
* Correspondence: aabudayyeh@mdanderson.org

${ }^{\dagger}$ Adi Diab and Ala Abudayyeh contributed equally to this work.

${ }^{6}$ Division of Internal Medicine, Section of Nephrology, The University of Texas

MD Anderson Cancer Center, 1515 Holcombe Blvd., Unit 1468, Houston, TX

77030, USA

Full list of author information is available at the end of the article
}

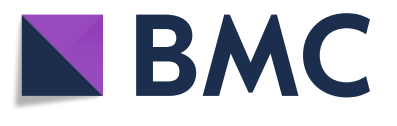

(c) The Author(s). 2019 Open Access This article is distributed under the terms of the Creative Commons Attribution 4.0 International License (http://creativecommons.org/licenses/by/4.0/), which permits unrestricted use, distribution, and reproduction in any medium, provided you give appropriate credit to the original author(s) and the source, provide a link to the Creative Commons license, and indicate if changes were made. The Creative Commons Public Domain Dedication waiver (http://creativecommons.org/publicdomain/zero/1.0/) applies to the data made available in this article, unless otherwise stated. 


\section{Introduction}

Immune checkpoint inhibition had a major clinical success in clinical oncology and impacted the treatment paradigm in many cancers. The approval indications for CPI has been progressively expanding including treatments the adjuvant setting [1-3]. Immune related adverse events (irAEs) are well described toxicities that are closely associated with CPI therapies and can involve any organ in the human body [4].

Renal toxicity associated with CPI incidence has been reported as low as $2 \%$ when nivolumab alone to $4.5 \%$ when combination nivolumab and ipilimumab has been used [2, 5-7]. Guidelines for the multidisciplinary management of irAEs have been published by the Society for Immunotherapy of Cancer (SITC) and the American Society of Clinical Oncology (ASCO) $[4,7,8]$; however, the data on renal management is limited and not consistent.

The CPI-related renal pathologies are varied. Besides acute tubulointerstitial nephritis, seven other biopsyproven kidney manifestations were published as case reports of nine patients on CPIs, including lupus nephropathy, thrombotic microangiopathy (TMA),nephrotic syndrome (focal segmental glomerulosclerosis (FSGS), two cases of minimal-change disease (MCD) [9], membranous nephropathy), pauci-immune glomerulonephritis [10], and two cases of IgA nephropathy [11-16]. The etiology of the reported kidney toxicity is not yet clear. Suggested mechanisms include direct lymphocytic cellular infiltration of renal interstitium, immune complex-mediated kidney injury, lupus nephritis, IgA, microangiopathic hemolytic anemia (TMA), or release of cytokines leading to podocyte foot process effacement (minimalchange disease and focal segmental glomerulosclerosis).

The current recommendations for the diagnosis and management of renal irAEs are not comprehensive due to the limited available data and understanding of the pathophysiology associated with renal irAEs. Therefore, we have reviewed a series of kidney biopsy cases of patients on CPIs in our institution to better understand the spectrum of injuries associated with irAEs and the treatments that were used.

\section{Methods}

This retrospective study was approved by the institutional review board in accordance with the Declaration of Helsinki. We retrospectively identified a total of 6412 patients who had received FDA approved CPI's at The University of Texas MD Anderson Cancer Center during 2008-2018. In addition, we collected all kidney biopsies (266) performed at MD Anderson in the same period. Of the 6412 patients, 15 patients were biopsied for suspected CPI-induced nephrotoxicity. However, an additional case in our biopsied database population that was treated with a non-approved CTLA-4 inhibitor (tremelimumab) was also identified, bringing the total cases to 16.

We collected age, sex, race/ethnicity, cancer diagnosis, name and class of CPI used, reason for kidney biopsy, underlying comorbidities including autoimmune disease, potentially nephrotoxic medications, serum creatinine at baseline, peak serum creatinine during AKI, date of last follow-up, urine sediment, proteinuria, other irAEs, serologic findings, and kidney biopsy findings.

We defined AKI using the AKIN criteria since it was used to define and categorize the severity of nephritis in the ASCO practice guidelines [17].

Patients' renal functions were followed up for at least 3 months post-AKI before categorizing renal recovery into persistent acute kidney injury, complete renal recovery and partial renal recovery, after creatinine had reached a stable value. Complete recovery of renal function was defined by an improvement in creatinine level post-AKI to a level less than $0.35 \mathrm{mg} / \mathrm{dL}$ above the baseline. Partial recovery was defined by the serum creatinine improving to a level between the baseline plus 0.35 $\mathrm{mg} / \mathrm{dL}$ and less than two times the baseline value. [18]

Complete remission in membranous nephropathy was defined by the random urine protein-to-creatinine ratios $<0.2 \mathrm{~g} / \mathrm{g}$ on at least three occasions along with a normal serum creatinine. [19]

\section{Results}

\section{Patient characteristics}

Sixteen patients developed AKI while on CPIs and required renal biopsies over the past 10 years at our institution. The characteristics of these patients, urine findings, AKI category, and associated renal pathology are summarized in Table 1.

Most cases identified were white men ( 1 case was a Hispanic man, and 4 cases were women), with a median age of 64 years (range, 38-77 years). Renal cell carcinoma, urothelial bladder cancer and melanoma were the most common malignancies ( 3 cases of RCC and 3 urothelial bladder cancer and 4 cases of melanoma), followed by multiple myeloma ( 2 cases) and 1 case each of chondroma, squamous cell cancer of the lung, adenocarcinoma of the lung, and Hodgkin lymphoma. Most cases occurred in the setting of nivolumab (antiPD-1) and pembrolizumab (anti-PD-1) use (6 cases each), a combination of nivolumab and ipilimumab (anti-CTLA-4) (2 cases), tremelimumab(anti-CTLA-4) ( 1 case), and atezolizumab (anti-PD-L1) (1 case). 7 patients had chronic kidney disease (CKD) at baseline:5 had CKD stage 3, and 2 had CKD stage 4.

\section{Clinical features}

The median time to development of AKI after starting a CPI was 14 weeks (range: 6-56 weeks). However, AKI 


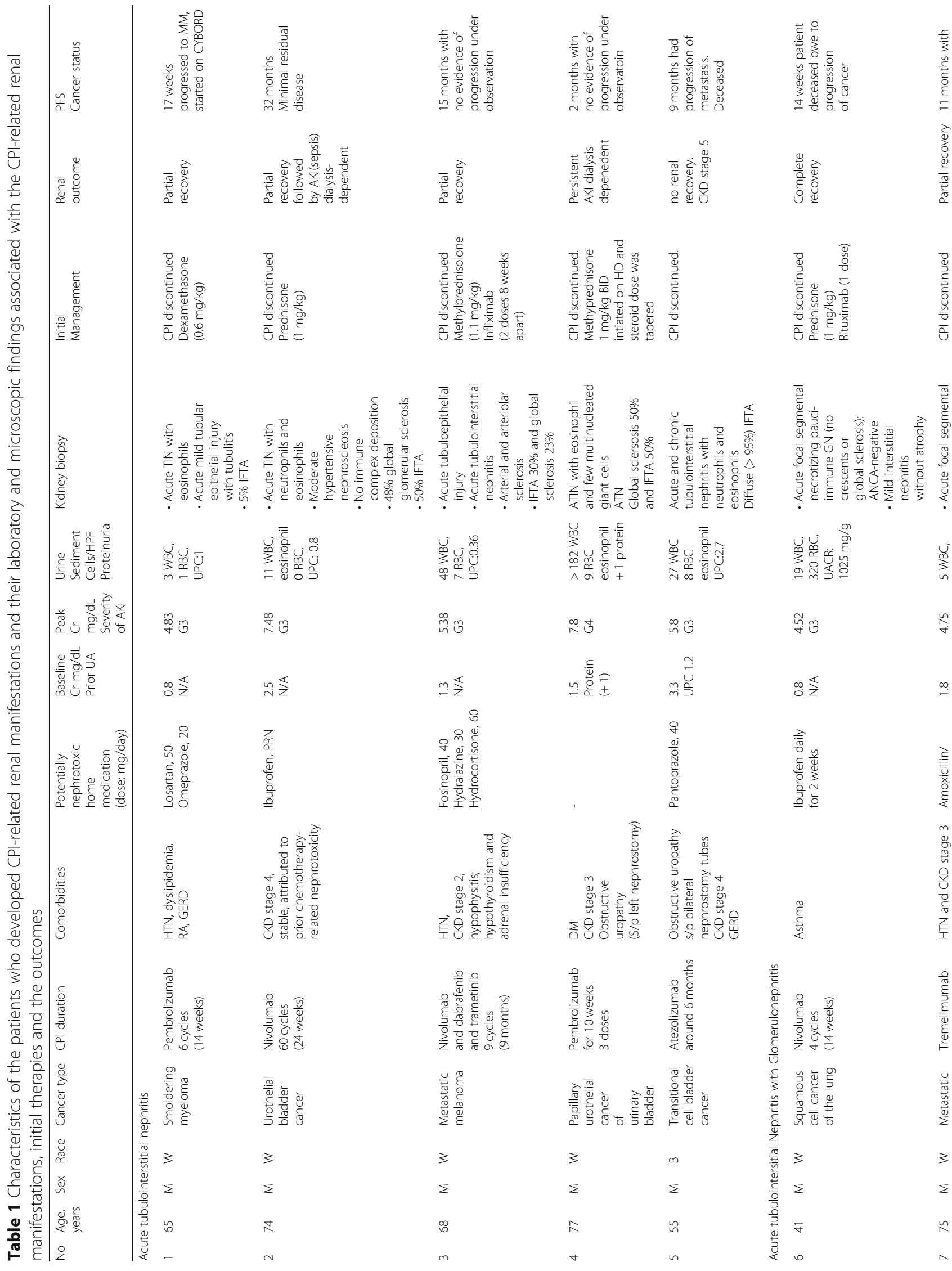

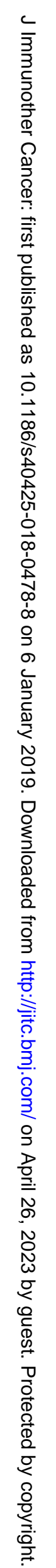




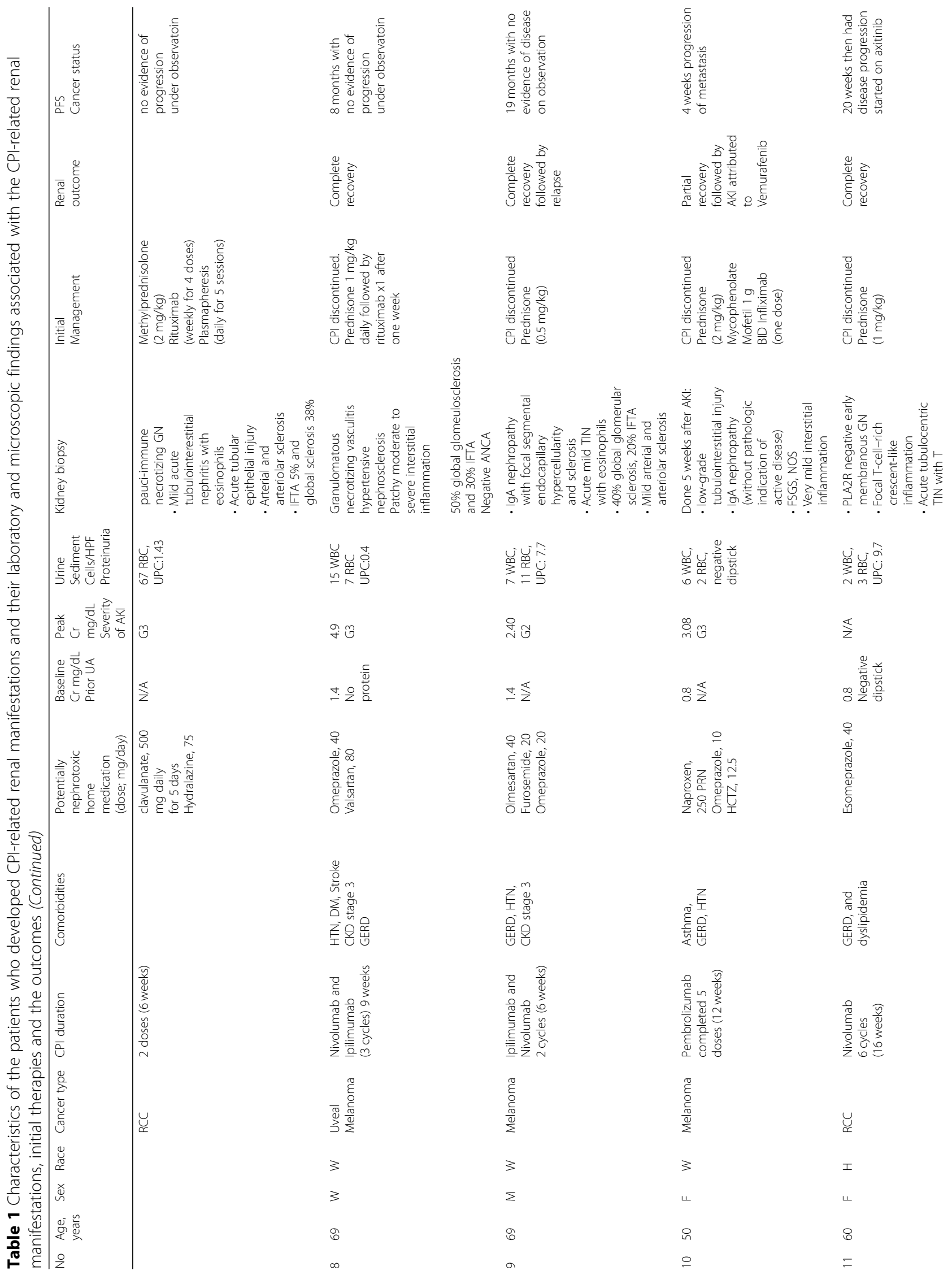

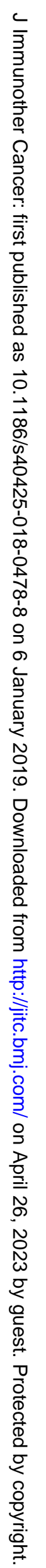




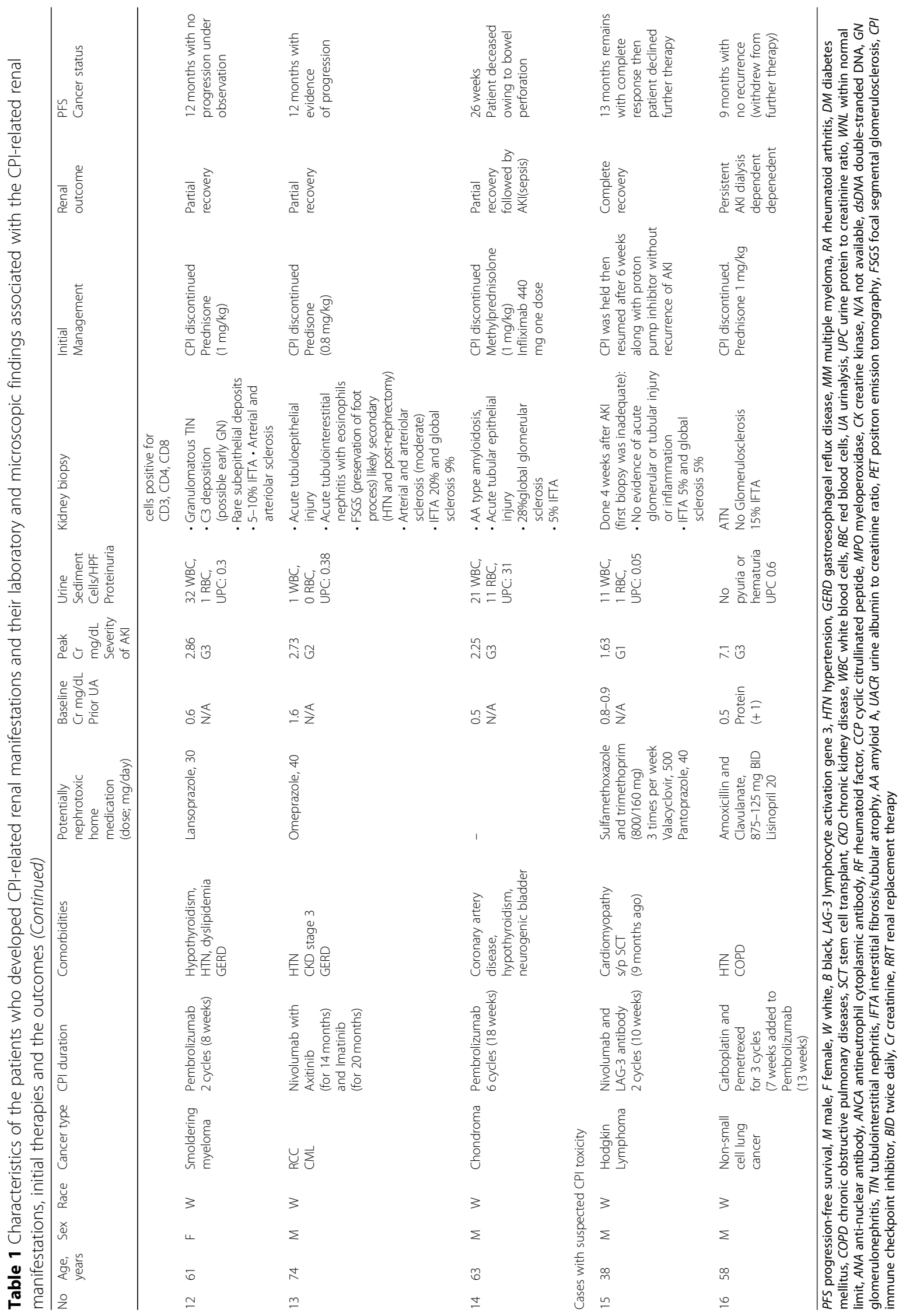

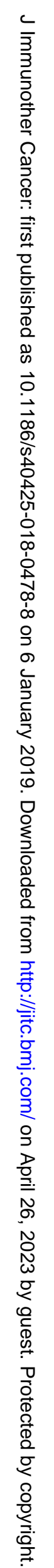


occurred within 9 weeks with the use of the CTLA-4 inhibitor tremelimumab or the combination of the CTLA-4 inhibitor ipilimumab and the PD-1 inhibitor nivolumab. All other patients on PD-1 inhibitors had longer durations to development of AKI: a median of 20 weeks (range, 10-56 weeks) with nivolumab alone and 13.5 weeks (range: $8-18$ weeks) with pembrolizumab alone.

The most common urine finding was sub-nephrotic proteinuria at time of acute kidney injury diagnosis (urine studies were done within $48 \mathrm{~h}$ of diagnosis in 13 out of 16 cases). The median urine protein-to-creatinine (UPC) ratio was $0.8 \mathrm{~g} / \mathrm{g}$ with a range of $0-31.3$ cases had $\leq 0.3 \mathrm{~g} / \mathrm{g}$ protein in the urine. 10 cases had proteinuria ranging from 0.3 to $3 \mathrm{~g} / \mathrm{g}$, and 3 cases had nephrotic-range proteinuria and hypoalbuminemia consistent with nephrotic syndrome and associated with renal pathologies of AA amyloidosis, membranous glomerulonephritis, or IgA nephropathy (one case each). Prior urinalysis was not available in most of the cases (11 out of 16) to compare the acuity of reported proteinuria. Pyuria (>5 white blood cells [WBC]/high-power field $[\mathrm{HPF}]$ ) with associated biopsy finding of tubulointerstitial inflammation was present in 7 patients but was absent in four patients despite histological evidence of tubulointerstitial nephritis in those patients, there was no clear association with type of CPI or use of steroids. Microscopic hematuria ( $>3$ red blood cells $[\mathrm{RBC}] / \mathrm{HPF}$ ) was present in eight of the patients in our series, two patients had $>50 \mathrm{RBC} / \mathrm{HPF}$ with a renal pathology of pauci-immune glomerulonephritis.

Among non-renal irAEs that developed during therapy with CPI (both Anti-PD-1 and Anti -CTLA-4), the most common irAE was hypothyroidism. Other irAEs were dermatitis, pnemonitis, colitis, esophagitis, adrenal insufficiency, and myositis. Majority of the non renal irAEs developed nephrotoxicity after or at the time of non renal irAE diagnosis. No correlation was observed between the severity and recovery of non-renal irAE with the renal one.

Summary of observed other irAEs in patients who developed CPI related nephrotoxcity and their outcome are included in Table 2.

\section{Renal pathologies and their associated clinical findings Acute tubulointerstitial nephritis}

Tubulointerstitial inflammation was the most common pathologic finding on biopsy, present in 14 of the 16 cases as either the main microscopic finding or as a mild form of interstitial inflammation in association with other glomerular pathologies.

As presented classically in the literature, our cases include 5 cases with only ATIN of which all had eosinophilic infiltration in addition to neutrophils except for one case. 2 cases were treated with pembrolizumab, 2 cases on Nivolumab, and 1 case was treated with Atezolizumab. 3 out of the 5 cases were also treated with either Ibuprofen or proton-pump inhibitors prior to CPI use which are also associated with ATIN [20].

\section{Acute tubulointersitial Nephritis \& Glomerulonephritis}

Pauci-immune glomerulonephritis (Fig. 1) Acute focal segmental necrotizing pauci -immune glomerulonephritis was noted in 3 cases, with nivolumab in 1 case, tremelimumab in 1 case, and nivolumab combined with ipilimumab, in 1 case. The patient on nivolumab had non-specific symptoms of fatigue and generalized weakness. Antineutrophil cytoplasmic antibody (ANCA) titer was negative.

The patient who developed pauci-immune glomerulonephritis related to tremelimumab had arthralgia, vasculitic rash, and pneumonitis. Serologic findings were remarkable for positive antinuclear antibodies (1:160), positive myeloperoxidase-antineutrophil cytoplasmic antibodies (MPO-ANCA; level $>8)$, negative anti-glomerular basement membrane (anti-GBM) antibodies, and normal complement.

The 3rd case we observed with microscopic finding of pauci-immune granulomatous necrotizing vasculitis occurred in a patient treated nivolumab combined with ipilimumab. The patient had AKI with nonspecific symptoms of poor appetite and fatigue. ANCA and anti-GBM titers were negative. Fungal stains and stains for acid-fast bacilli and BK polyomavirus were negative which are also associated with granulomatous tubulointerstitial inflammation. In all 3 vasculitis cases urine studies indicated microscopic hematuria, pyuria and sub nephrotic proteinuria were seen.

IgA nephropathy (Fig. 2) IgA nephropathy developed in a patient receiving the combination therapy of ipilimumab and nivolumab and in a patient receiving pembrolizumab. Both patients had hypertension with no prior history of IgA nephropathy. No previous urine studies were available for evaluation of prior reported microscopic hematuria or proteinuria. The patient who was receiving ipilimumab combined with nivolumab had preexisting stable CKD stage 3 (eGFR $55-60 \mathrm{~mL} / \mathrm{min} /$ $1.73 \mathrm{~m}^{2}$ ) and had an increase in creatinine level from a baseline of $1.3 \mathrm{mg} / \mathrm{dL}$ to $2.4 \mathrm{mg} / \mathrm{dL}$, with pyuria and hematuria (7 and 11 cells/HPF respectively) and nephrotic range proteinuria (UPC ratio: $7.7 \mathrm{~g} / \mathrm{g}$ ) after completing the 2nd cycle. Kidney biopsy showed IgA nephropathy with focal, segmental endocapillary hypercellularity and sclerosis and mild ATIN with eosinophils.

The 2nd case developed AKI after receiving the 5th cycle of pembrolizumab. Urinalysis was positive for 
Table 2 Observed irAEs in patients who developed CPI related nephrotoxcity and their outcome

\begin{tabular}{|c|c|c|c|c|c|}
\hline Patient \# & $\mathrm{CPI}$ & AKI severity & Assosciated irAE & Relation to AKI diagnosis & Renal and non renal irAE outcome \\
\hline 11 & Nivolumab & $\begin{array}{l}\text { Nephrotic } \\
\text { syndrome }\end{array}$ & Hypothyrodisim (G2) & 4 weeks prior to $\mathrm{AKI}$ & $\begin{array}{l}\text { Persistent hypothyrodisim } \\
\text { Complete remission of nephrotic } \\
\text { syndrome }\end{array}$ \\
\hline 14 & Pembrolizumab & G3 & Colitis (G3) & 2 weeks prior to $\mathrm{AKI}$ & $\begin{array}{l}\text { Diarrhea and renal function } \\
\text { improved partially then patient } \\
\text { developed } 2 \text { nd AKI }\end{array}$ \\
\hline 2 & Nivolumab & G3 & Elevated dsDNA and RNP titers & At the time of AKI diagnosis & $\begin{array}{l}\text { Titers became undetectable } \\
\text { after } 4 \text { week } \\
\text { Partial renal recovery }\end{array}$ \\
\hline 6 & Nivolumab & G3 & Hypothyrodisim (G2) & 10 weeks prior to $\mathrm{AKI}$ & $\begin{array}{l}\text { Persistent hypothyrodisim } \\
\text { Complete renal recovery }\end{array}$ \\
\hline 3 & Nivolumab & G3 & Myositis & 6 weeks after AKI & $\begin{array}{l}\text { Myosisits had resolved } \\
\text { Partial renal recovery }\end{array}$ \\
\hline 7 & Tremelimumab & G3 & $\begin{array}{l}\text { Dermatitis (G1) } \\
\text { Pneumonitis (G2) }\end{array}$ & At the time of AKI diagnosis & $\begin{array}{l}\text { Dermatitis and pneumonitis } \\
\text { had resolved within } 2 \text { week } \\
\text { Partial renal recovery }\end{array}$ \\
\hline 15 & Nivolumab & G1 & $\begin{array}{l}\text { Hypothyrodisim (G2) } \\
\text { Esophagitis (G2) }\end{array}$ & 5 weeks prior to $\mathrm{AKI}$ & $\begin{array}{l}\text { Esophagitis and AKI had } \\
\text { fully recovered } \\
\text { Persistent hypothyrodisim }\end{array}$ \\
\hline 10 & Pembrolizumab & G3 & $\begin{array}{l}\text { Dermatitis (G1) } \\
\text { Pneumonitis (G2) }\end{array}$ & At the time of AKI diagnosis & $\begin{array}{l}\text { Dermatitis and pneumonitis } \\
\text { had resolved within } 1 \text { week } \\
\text { Partial renal recovery }\end{array}$ \\
\hline 8 & $\begin{array}{l}\text { Nivolumab and } \\
\text { Ipilimumab }\end{array}$ & G3 & $\begin{array}{l}\text { Dermatitis (G1) } \\
\text { Thyroditis (G3) } \\
\text { Adrenal insuffiency (G1) }\end{array}$ & 5 weeks prior to $\mathrm{AKI}$ & $\begin{array}{l}\text { Persistent hypothyrodisim } \\
\text { and adrenal insuffiency } \\
\text { Complete renal recovery }\end{array}$ \\
\hline
\end{tabular}

Common Terminology Criteria for Adverse Events (CTCAE)

Grade 1 Mild; asymptomatic or mild symptoms; clinical or diagnostic observations only; intervention not indicated

Grade 2 Moderate; minimal, local or noninvasive intervention indicated; limiting ageappropriate instrumental ADL

Grade 3 Severe or medically significant but not immediately life-threatening; hospitalization or prolongation of hospitalization indicated; disabling; limiting self care ADL

Grade 4 Life-threatening consequences; urgent intervention indicated

$C P I$ immue Checkpoint inhibitor, $A K I$ acute kidney injury, irAE immue related adverse events

pyuria with no hematuria or proteinuria. Biopsy showed IgA nephropathy with focal, segmentally sclerotic glomeruli, without evidence of active disease along with mild ATIN. Of note, on the second case, the biopsy was performed 5 weeks after discontinuation of the CPIs and while the patient was on prednisone, which may account for the lack of significant inflammation in the biopsy.

Membranous nephropathy (Fig. 3) One patient who had had negative urinalysis results before starting nivolumab developed nephrotic-range proteinuria after $6 \mathrm{cy}$ cles (16 weeks of therapy) with a UPC ratio of $9.7 \mathrm{~g} / \mathrm{g}$ and no hematuria, pyuria, or significant change in eGFR. The pathology showed features of early membranous glomerulonephritis negative for anti-phospholipase -A2receptor (PLA2R) autoantibodies with focal T cell-rich crescent-like inflammation and acute glomerulocentricnephritis with $\mathrm{T}$ cells positive for $\mathrm{CD} 3, \mathrm{CD} 4$, and $\mathrm{CD} 8$. The presence of concurrent ATIN, and the patient's complete recovery (UPC ratio improved to $<0.5 \mathrm{~g} / \mathrm{g}$ ) after CPI discontinuation and steroid therapy suggested that the membranous nephropathy was related to CPI rather than to progression of the underlying malignancy.
The rest of the secondary serologic analysis, including the hepatitis panel, was negative.

C3 glomerulopathy One patient with smoldering multiple myeloma was treated with pembrolizumab for 2 cycles and then developed AKI with microscopic hematuria and pyuria. The patient had granulomatous tubulointerstitial nephritis. Glomeruli were normal in appearance without inflammation. However, there was granular C3-only deposition on immunofluorescence with corresponding rare, large sub-epithelial deposits by electron microscopy and normal serum C3 levels. Lack of immunoglobulin and light chain deposition was confirmed by immunofluorescence staining of proteinase-treated paraffin sections. The patient had no evidence of infection and had stable free kappa light chains. These findings suggested early features of C3 glomerulopathy.

Focal segmental glomerulosclerosis (FSGS) FSGS was observed in the kidney biopsy of one case treated with nivolumab as monotherapy. The patient had hypertension and proteinuria, but it was less than $0.5 \mathrm{~g}$ per day 


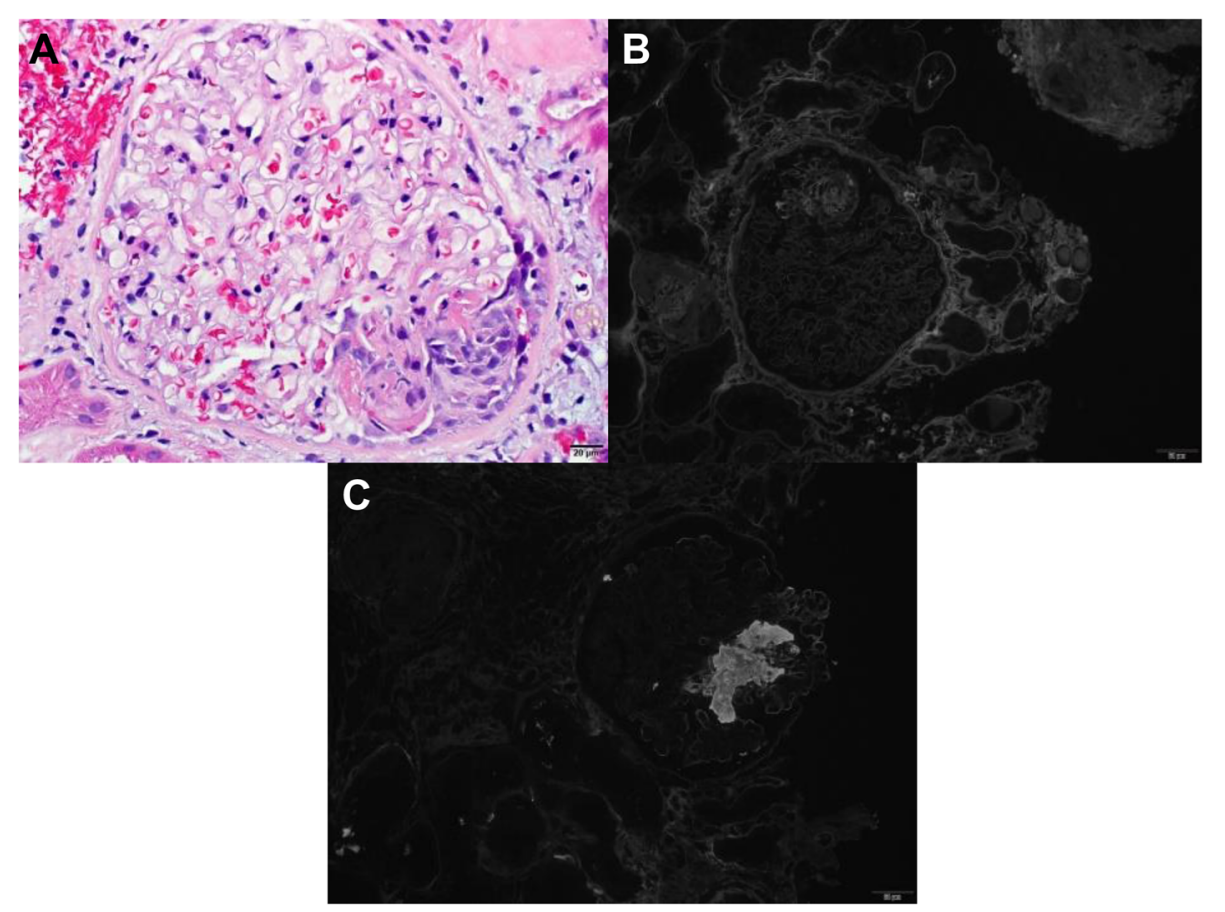

Fig. 1 Two cases showed pauci-immune glomerulonephritis characterized by focal, segmental glomerulonecrosis (a, H\&E) without immune complex deposition (b, lgG immunofluorescence) and with fibrin deposition within the lesions (c, fibrinogen immunofluorescence)

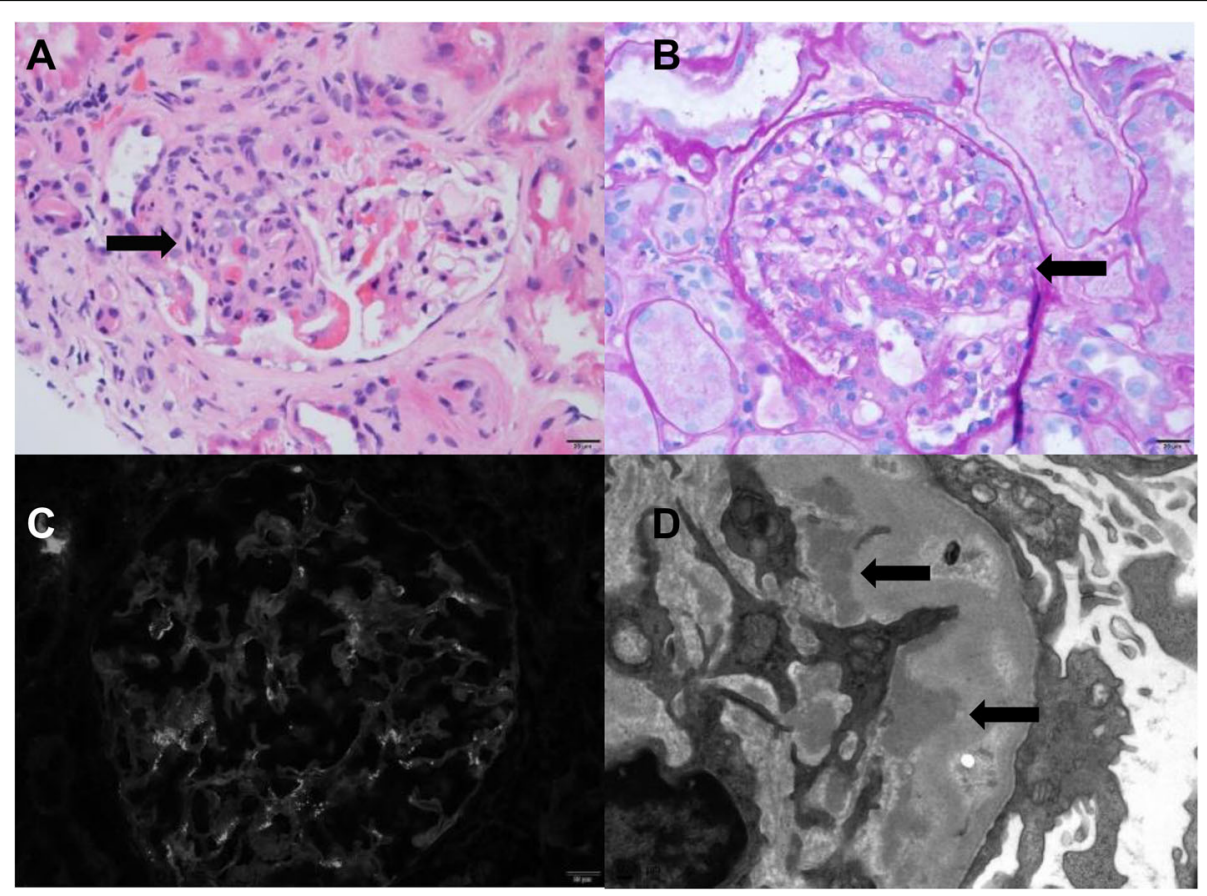

Fig. 2 Two cases showed IgA nephropathy, one of which was characterized by segmental mesangial and endocapillary hypercellularity seen on H\&E (a) and PAS stains (b), indicated by arrows. There were IgA-dominant immune complex deposits (c, IgA immunofluorescence) with numerous mesangial electron dense deposits ultra-structurally, indicated by arrows (d, electron microscopy). 


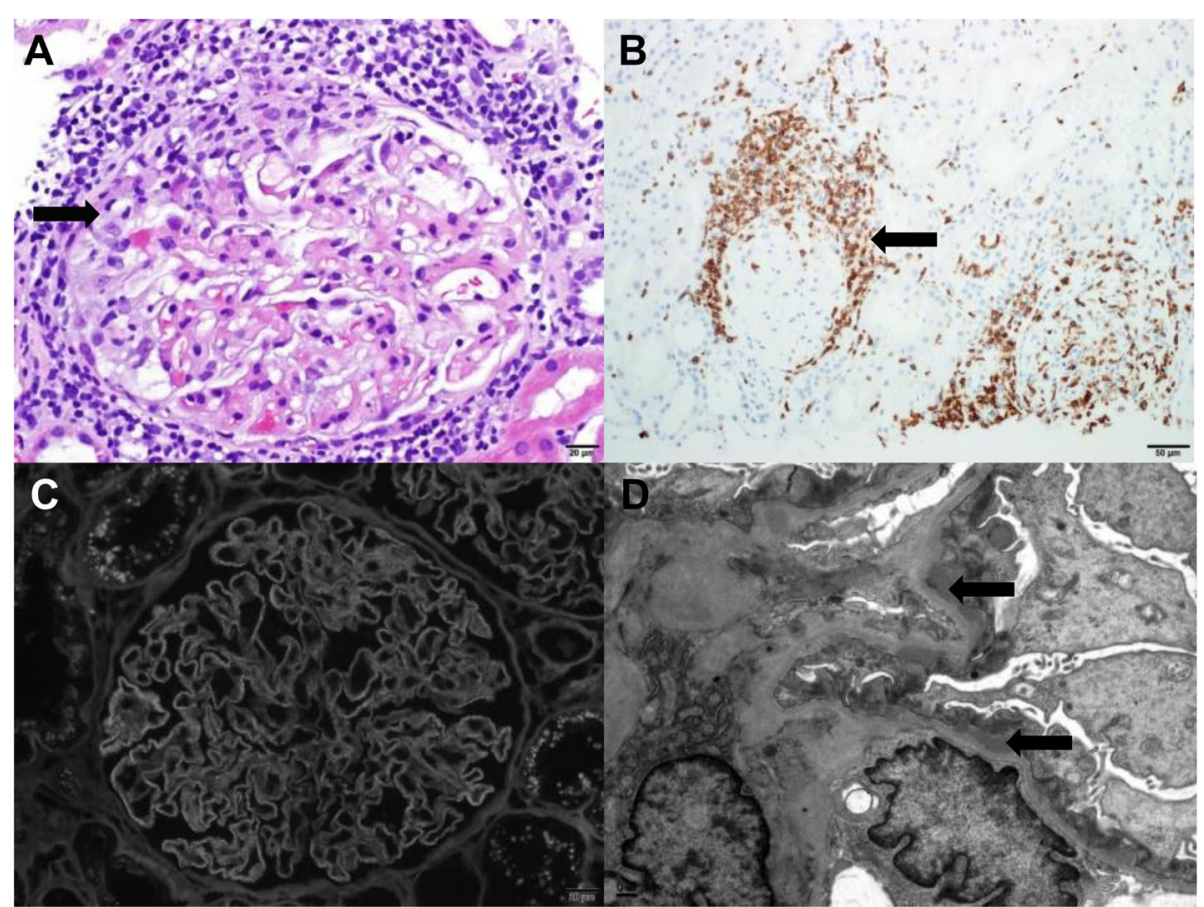

Fig. 3 A single case of membranous glomerulonephritis which showed a focal area of crescent-like inflammation and glomerulocentric tubulointerstitial nephritis (a, H\&E, arrow indicates crescent like inflammation) which was T-cell rich (b, CD3 immunohistochemistry, arrow indicated CD3 positive cells). There was diffuse capillary immune complex deposition (c, lgG immunofluorescence) with numerous subepithelial electron-dense deposits, indicated by arrows (d, electron microscopy)

(UPC ratio $<0.5 \mathrm{~g} / \mathrm{g}$ ) with no hematuria or significant pyuria noted on the urinalysis. Electron microscopy showed preservation of foot processes which is suggestive of secondary focal segmental glomerulosclerosis. Again, acute tubulointerstitial nephritis was noted with eosinophilia.

AA amyloidosis (Fig. 4) After 18 weeks (6 cycles) of pembrolizumab, a patient with chondroma developed AKI with nephrotic-range proteinuria (UPC ratio: $31 \mathrm{~g}$ / g) and severe colitis. The kidney biopsy was positive for amyloid on Congo red and thioflavin T. Immunofluorescence was negative for light chains, and mass spectroscopy confirmed AA amyloid. Patient was started on steroids $48 \mathrm{~h}$ prior to the biopsy and could explain the lack of ATIN in the pathology although there was evidence of microscopic hematuria and pyuria on the urinalysis.

Comparison of the characteristics and renal outcomes of patients with renal pathologies related to CPI use between the current study and the previously published case reports are summarized in Table 3.

\section{Treatment}

CPIs were discontinued in 15 cases and held for 6 weeks in one case of the studied cases at the time of AKI diagnosis. Most of the patients received steroids at the time of AKI diagnosis except two patients. One who had mild nephritis, in whom CPI was held, and another who had severe kidney disease and poor residual renal function (seen in interstitial fibrosis with tubular atrophy (IFTA) > $90 \%$ on biopsy). Additional immunosuppressant agents were used as indicated by the associated glomerulonephritis in the pathology. The dose, form, or duration of steroid treatment did not follow any guideline. The initial used dose of prednisone ranged from $0.5-4 \mathrm{mg} / \mathrm{kg} /$ day. The prednisone was tapered off over 4-24 weeks depending on the renal pathology and recurrence of renal disease.

\section{Renal function and survival outcomes}

Three of the 5 ATIN cases all had partial renal recovery after prednisone and one of which had also infiliximab ( 2 doses). The 2 cases with no renal response, one had poor residual renal function from severe chronic kidney disease with associated IFTA > 90\%, CPI was held, and no steroids were given, and the other case had associated acute tubular necrosis and remained hemodialysis dependent as of 12 weeks post AKI diagnosis despite prednisone therapy.

In our glomerulonephritis cases, membranous nephropathy, granulomatous with C3 glomerular deposition, and focal segmental glomerulosclerosis, and one of the 2 cases of CPI-related IgA nephropathy had 


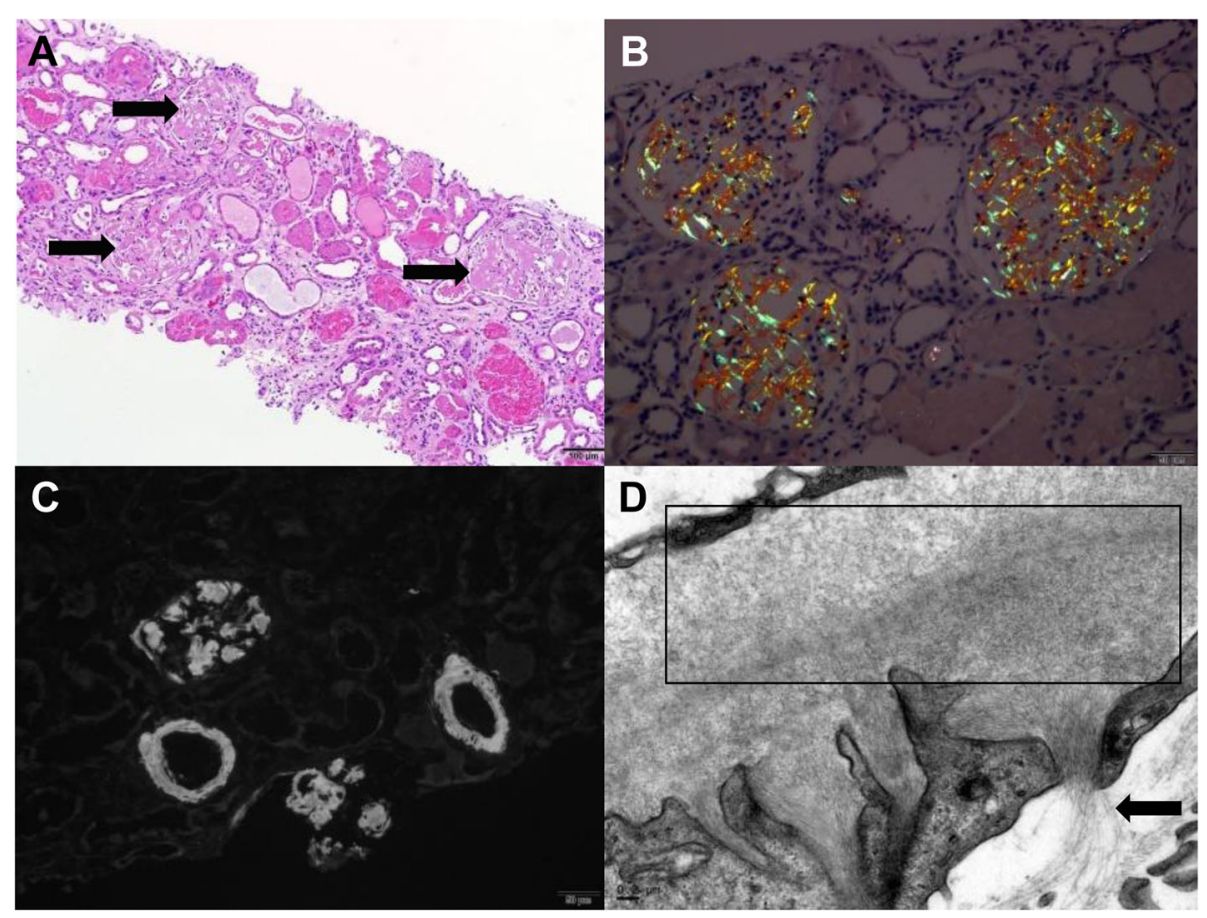

Fig. 4 In the case of amyloidosis, the glomeruli showed diffuse mesangial expansion by amorphous eosinophilic matrix, indicated by arrows (a, $\mathrm{H} \& \mathrm{E}$ ) that showed green birefringence under polarized light by Congo red stain (b) and diffuse $3+$ fluorescence (Thioflavin $T$ stain) of deposits in glomeruli and arterioles (c). Abundant fibrils measuring $8-10 \mathrm{~nm}$ were identified by electron microscopy, area of dense fibril deposition within the box, less dense fibril deposition indicated by arrows (d)

complete or partial recovery after starting prednisone $(0.5$ $\mathrm{mg} / \mathrm{kg}-3 \mathrm{mg} / \mathrm{kg}$ ). The two ANCA negative pauci-immune glomerulonephritis patients had complete recovery of renal function after discontinuing CPI and starting prednisone and rituximab for treatment of pauci immune GN. The 3rd patient with ANCA positive pauci immune GN underwent treatment with steroids, plasmapheresis, and rituxi$\mathrm{mab}$ as indicated for creatinine $>4.0 \mathrm{mg} / \mathrm{dl}$ and possible lung involvement. The patient with AA amyloid had partial renal recovery after steroid treatment and due to continued colitis received infliximab and later progressed to AKI due to sepsis. The second IgA case had partial renal response after steroids, mycophenolate mofetil and then one dose of infliximab due to failure of initial response.

Three of the 16 cases died because of disease progression. All 13 surviving patients continued treatment, with 5 being on active therapy and 8 staying on surveillance.

We included the disease progression free survival (PFS) of the 16 patients in Table 1 . However, we are not able to conclude a disease response or PFS benefit in these patients since we do not have in this current population patients who were treated with CPIs and didn't develop nephrotoxicity to make such comparison.

\section{Discussion}

We report 16 cases, 5 with typical ATIN with no associated glomerulonephritis which is the most commonly reported etiology for AKI related to CPIs [21] . However, we have also presented ATIN associated with glomerulopathies in nine out of the 16 cases. Some of these glomerulopathies have not been reported in the literature to be associated with CPI use (MPO-ANCA positive pauci-immune glomerulonephritis, C3 staining, or AA amyloid). The treatments of these glomerulopathies were varied and not limited to steroids but included other immunosuppressive medications in steroids refractory cases and as a standard of care to treat the glomerulopathies.

Immunotherapy-related acute interstitial nephritis $[22,23]$ could be due to the loss of tolerance of drugspecific effector $\mathrm{T}$ cells with the inhibition of PD-1 signaling. These are $\mathrm{T}$ cells that were primed during a prior nephritogenic drug exposure. Another proposed mechanism is the development of autoimmunity to kidney self-antigens after the loss of self-tolerance and potentiation of antigen recognition after blocking of the CTLA-4 or PD-1 pathway, which plays an important role in regulating peripherally and at the level of target organs, respectively [24].

The types of nephropathies induced by the CPI class vary tremendously, even when induced by a single agent such as nivolumab. For a given glomerulopathy related to CPIs, the severity and the response to steroids can also differ, partly due to patient differences. Overall, the variety of $\mathrm{CPI}$-induced renal manifestations suggests 
Table 3 Comparison of the characteristics and renal outcomes of patients with CPI related nephropathy between the current study and the previously published case reports

\begin{tabular}{|c|c|c|c|c|c|c|}
\hline Case & Renal Manifestation & $\begin{array}{l}\text { Urine studies/ } \\
\text { Serology }\end{array}$ & Malignancy & Immunotherapy & Therapy & Response \\
\hline \multicolumn{7}{|c|}{ Nephrotic syndrome cases in relation to immune checkpoint agents } \\
\hline Daanen et al. [13] & FSGS & - & $\mathrm{RCC}$ & Nivolumab & $\begin{array}{l}\mathrm{D} / \mathrm{C}+\text { steroids }+ \\
\mathrm{MMF}\end{array}$ & $\begin{array}{l}\text { Remission } \\
\text { followed by } \\
\text { relapse }\end{array}$ \\
\hline $\begin{array}{l}\text { Kitchlu } \\
\text { et al. [14] }\end{array}$ & MCD & - & $\begin{array}{l}\text { Hodgkin } \\
\text { lymphoma }\end{array}$ & Pembrolizumab & $\mathrm{D} / \mathrm{C}+$ steroids & $\begin{array}{l}\text { Remission } \\
\text { (partial) }\end{array}$ \\
\hline $\begin{array}{l}\text { Kitchlu } \\
\text { et al. [14] }\end{array}$ & MCD & - & Melanoma & Ipilimumab & $\mathrm{D} / \mathrm{C}+$ steroids & Remission \\
\hline Lin et al. [9] & $\begin{array}{l}\text { Membranous Nephropathy } \\
\text { (PLA2R neg.) }\end{array}$ & - & Melanoma & Nivolumab & $\mathrm{D} / \mathrm{C}+$ steroids & $\begin{array}{l}\text { Remission } \\
\text { (partial) }\end{array}$ \\
\hline Current study (\#11) & $\begin{array}{l}\text { Membranous Nephropathy } \\
\text { (PLA2R neg.) }\end{array}$ & - & $\mathrm{RCC}$ & Nivolumab & $\mathrm{D} / \mathrm{C}+$ steroids & Remission \\
\hline \multicolumn{7}{|c|}{ IgA nephropathy cases in relation to immune checkpoint agents } \\
\hline Jung et al. [16] & $\begin{array}{l}\text { AKI grade } 4 \\
\text { Cellular crescents with necrosis } \\
\text { Sub-epithelial desposition. }\end{array}$ & $\begin{array}{l}\text { Proteinuria and } \\
\text { hematuria }\end{array}$ & $\begin{array}{l}\text { Clear cell } \\
\text { Kidney cancer }\end{array}$ & Nivolumab & $\begin{array}{l}\text { D/C, steroids } \\
\text { and RRT }\end{array}$ & $\begin{array}{l}\text { Recovery } \\
\text { (RRT was d/c } \\
\text { after } 5 \text { months) }\end{array}$ \\
\hline Kishi et al. [15] & $\begin{array}{l}\text { AKI grade } 2 \\
\text { Mesangial exp. with no crescents } \\
\text { or endocapillary hypercellularity }\end{array}$ & $\begin{array}{l}\text { Sub nephrotic } \\
\text { proteinuria. } \\
\text { Hematuria }\end{array}$ & Lung SCC & Nivolumab & $\mathrm{D} / \mathrm{C}$ & $\begin{array}{l}\text { Remission } \\
\text { (Complete) }\end{array}$ \\
\hline Current study (\#9) & $\begin{array}{l}\text { AKI grade } 2 \\
\text { endocapillary hypercellularity }\end{array}$ & $\begin{array}{l}\text { Nephrotic range } \\
\text { proteinuria } \\
\text { Pyuria and } \\
\text { hematuria }\end{array}$ & Melanoma & $\begin{array}{l}\text { Nivolumab+ } \\
\text { Ipilimumab }\end{array}$ & $\mathrm{D} / \mathrm{C}$ and steroids & $\begin{array}{l}\text { Remission } \\
\text { followed } \\
\text { by relapse }\end{array}$ \\
\hline Current study (\#10) & $\begin{array}{l}\text { AKI grade } 3 \\
\text { No Glomerular } \\
\text { proliferative lesions* }\end{array}$ & $\begin{array}{l}\text { No proteinuria } \\
\text { No hematuria } \\
\text { +pyuria }\end{array}$ & Melanoma & Pembrolizumab & $\begin{array}{l}\text { D/C and steroids, } \\
\text { MMF, and infliximab }\end{array}$ & Partial recovery \\
\hline \multicolumn{7}{|c|}{ Pauci-immune GN cases in relation to immune checkpoint agents } \\
\hline Van den Brom et al. [12] & $\begin{array}{l}\text { GPA ** } \\
\text { Dysmorphic erythrocytes and proteinuria } \\
\text { Extra renal: Cutaneous vasculitis } \\
\text { Stable lung nodule }\end{array}$ & $\begin{array}{l}+ \text { PR3-ANCA } \\
\text { C; normal }\end{array}$ & $\begin{array}{l}\text { Malignant } \\
\text { Melanoma }\end{array}$ & $\begin{array}{l}\text { Ipilimumab } \\
\text { followed by } \\
\text { Pembrolizumab }\end{array}$ & $\begin{array}{l}\text { Cyclosporine } \\
\text { and steroids }\end{array}$ & Remission \\
\hline Cusnir et al. [10] & $\begin{array}{l}\text { GPA } \\
\text { Focal proliferative GN } \\
\text { Extra renal; Cutaneous vasculitis } \\
\text { sinusitis }\end{array}$ & $\begin{array}{l}+ \text { PR3-ANCA } \\
\text { C; N/A }\end{array}$ & $\begin{array}{l}\text { Malignant } \\
\text { Melanoma }\end{array}$ & $\begin{array}{l}\text { Nivolumab+ } \\
\text { Ipilimumab }\end{array}$ & $\begin{array}{l}\text { steroids and } \\
\text { rituximab }\end{array}$ & Not Stated \\
\hline Current study (\#6) & $\begin{array}{l}\text { Focal necrotizing pauci-immune } \\
\text { glomerulonephritis with no crescents } \\
\text { Extra renal; N/A }\end{array}$ & $\begin{array}{l}\text { Negative ANCA } \\
\text { C; N/A } \\
\text { G3 }\end{array}$ & NSCLC (SCC) & Nivolumab & $\begin{array}{l}\mathrm{D} / \mathrm{C} \text {, steroids } \\
\text { and rituximab }\end{array}$ & $\begin{array}{l}\text { Complete } \\
\text { recovery }\end{array}$ \\
\hline Current study (\#7) & $\begin{array}{l}\text { Focal segmental pauci-immune } \\
\text { necrotizing glomerulonephritis } \\
\text { Extra renal; N/A }\end{array}$ & $\begin{array}{l}+ \text { MPO-ANCA } \\
\text { C; normal } \\
\text { G3 }\end{array}$ & $\mathrm{mRCC}$ & Tremelimumab & $\begin{array}{l}\text { D/C, steroids, } \\
\text { plasmaphresis } \\
\text { and rituximab }\end{array}$ & $\begin{array}{l}\text { Partial } \\
\text { recovery }\end{array}$ \\
\hline Current study (\#8) & $\begin{array}{l}\text { Granulomatous necrotizing vasculitis } \\
\text { Extra renal; N/A }\end{array}$ & $\begin{array}{l}\text { Negative ANCA } \\
\text { C3/4 normal }\end{array}$ & $\begin{array}{l}\text { Uveal } \\
\text { Melanoma }\end{array}$ & $\begin{array}{l}\text { Nivolumab+ } \\
\text { Ipilimumab }\end{array}$ & $\begin{array}{l}\mathrm{D} / \mathrm{C} \text {, steroids } \\
\text { and rituximab }\end{array}$ & $\begin{array}{l}\text { Complete } \\
\text { recovery }\end{array}$ \\
\hline \multicolumn{7}{|c|}{ Anti-dsDNA cases in relation to immune checkpoint agents } \\
\hline Fadel et al. [11] & $\begin{array}{l}\text { AKI with proteinuria } \\
\text { Extramembranous and mesangial } \\
\text { deposits (IgG, IgM, C }, C 1 q)\end{array}$ & $\begin{array}{l}+ \text { dsDNA } \\
\text { C; normal }\end{array}$ & $\begin{array}{l}\text { Metastatic } \\
\text { Melanoma }\end{array}$ & Ipilimumab & $\mathrm{D} / \mathrm{C}$ & $\begin{array}{l}\text { Partial renal } \\
\text { recovery } \\
\text { dsNDA; } \\
\text { not detectable }\end{array}$ \\
\hline Current study (\#2) & $\begin{array}{l}\text { AKI with proteinuria } \\
\text { ATIN with no I.C. deposition GN }\end{array}$ & $+\mathrm{dsDNA}$ and RNP & $\begin{array}{l}\text { Bladder } \\
\text { cancer }\end{array}$ & Nivolumab & $\mathrm{D} / \mathrm{C}$ and steroids & $\begin{array}{l}\text { Partial renal } \\
\text { recovery } \\
\text { dsNDA } \\
\text { and RNP; } \\
\text { not detectable }\end{array}$ \\
\hline
\end{tabular}

FSGS focal segemental glomerulosclerosis, MCD mininmal change disease, D/C immune checkpoint agent was discontinued, Neg Negative, PLA2R antiphospholipase-A2 receptor, AKI acute kidney injury, I.C immune complex, GN glomerulonephritis, C, complement, Exp. expansion, $A K I$ acute kidney injury, ATIN acute tubulointerstitial nephritis, $R R T$ renal replacement therapy, GPA granulomatosis with polyangiitis, PR3 proteinase 3, ANCA antineutrophil cytoplasmic antibodies, MPO myeloperoxidase, N/A not available, NSCLC non-small cell lung cancer, mRCC metastatic renal cell carcinoma, dsDNA double stranded DNA ${ }^{*}$ Renal biospy was done 5 weeks post treatment with steroid, MMF and infliximab

**Presumptive diagnosis. Renal Biopsy was not reported 
multiple complex mechanisms that should be further elucidated.

Autoantibody development was believed to explain the variability in immune- related adverse effects $[25,26]$. We observed one case with acute interstitial nephritis that was refractory to high-dose corticosteroids. The patient did respond partially to infliximab. This was also demonstrated in one of the IgA cases where patient was refractory to high dose steroids and Cellcept and finally responded after infliximab, suggesting that adding anti-tumor necrosis factor alpha could have mediated some of the renal inflammation. The treatment success may be due to infliximab's immediate action to block TNF-alpha, which is usually upregulated in patients on CPIs [23]. The renal benefit could be direct or indirect, via a decrease in cytokine release that would otherwise contribute to acute tubular necrosis. However, a delayed effect of mycophenolate mofetil use, which can take several weeks, cannot be excluded in one of our cases [27]. Adding infliximab as a second-line therapy for cases with irAEs that are resistant to steroids has been suggested previously $[27,28]$, but has not specifically reported in previous cases of nephritistype irAEs.

Based on the variety of renal pathologies noted in our 16 patients who developed AKI while on CPIs, we recommend a kidney biopsy in patients with grade 2 or above renal injury and/or patients with unexplained proteinuria of greater than one gram/day. At baseline, the urinalysis, spot protein to creatinine ratio, antinuclear antibody levels, and anti-double-stranded DNA levels could be obtained before initiation of the CPI therapy.

\section{Limitations}

Patients with other irAEs may have also undergone treatment with steroids or other forms of immunosuppression that further ameliorate the renal dysfunction prior to the renal biopsy. In addition, because of the retrospective nature of the study we do lack baseline urinalysis prior to use of CPI and therefore cannot completely exclude the presence of underlying renal pathologies prior to CPI use. In addition, although majority of our cases with renal pathologies were treated with anti-PD-1 agents we cannot conclude that ATIN was more prevalent in this class of medications since out of the 6412 patients identified more than half (3608) were treated with anti-PD1 agents. Needed are prospective studies with urinalysis, proteinuria evaluation at baseline, during CPI and pre-toxicity, at time of toxicity and at the time of toxicity resolution to more accurately identify and characterize renal irAEs and response to immune suppression, in addition to obtaining early renal consult and renal biopsy when indicated.

Acknowledgements

Not applicable.
Funding

The University of Texas MD Anderson Cancer Center is supported in part by the National Institutes of Health through Cancer Center Support Grant P30CA016672.

Availability of data and materials

All data generated or analyzed during this study are included in this published article.

\section{Authors' contributions}

Data acquisition was performed by AA, OM. US, SM. WG, AT and LG performed the histological examination of the kidney biopsies and contributed in writing the pathology section of the manuscript. The manuscript preparation was performed by $A A, A D$, and $O M$ and edited by US and SC. All the authors contributed to the quality control data, analysis, interpretation of data and writing and final proof of paper. All authors read and approved the final manuscript.

Ethics approval and consent to participate

This retrospective study was approved by the institutional review board in accordance with the principles of the Declaration of Helsinki.

Consent for publication

Institution consent form (MD Anderson).

\section{Competing interests}

Dr. Yee is Consultant for Immatics US, Berkeley Lights, Adaptive Biotechnologies, and Torque Biologics and he is a member of Parker Institute of Immunotherapy for support.

Dr. Tannir is on an advisory board and receiving honoraria from Pfizer., Nektar Therapeutics, and Oncorena. He is as well on an advisory board of ARMO BioSciences and receiving honoraria from Bristol-Myers Squibb, Novartis, Exelisis, and Eiasi Med Research.

Dr. Diab has research funding from NEKTAR therapeutics, Idera Therapeutics, Pfizer, and Bristol Myers Squibb.

Dr. Suarez-Almazor is the recipient of a K24 career award from NIAMS (NIAMS K24 AR053593) and she has received consultant fees from Bristol Myers Squibb.

\section{Publisher's Note}

Springer Nature remains neutral with regard to jurisdictional claims in published maps and institutional affiliations.

\section{Author details}

${ }^{1}$ Department of Nephrology, McGovern Medical School, The University of Texas Health Science Center at Houston, Houston, TX, USA. ${ }^{2}$ Division of Nephrology, Department of Medicine, David Geffen School of Medicine, University of California, Los Angeles, Los Angeles, CA, USA. ${ }^{3}$ Institute for Academic Medicine and Weill Cornell Medical College, Houston Methodist Cancer Center, Houston, TX, USA. ${ }^{4}$ Department of Pathology, McGovern Medical School, The University of Texas Health Science Center at Houston, Houston, TX, USA. ${ }^{5}$ Department of Pathology, Houston Methodist Hospital, Houston, TX, USA. 'Division of Internal Medicine, Section of Nephrology, The University of Texas MD Anderson Cancer Center, 1515 Holcombe Blvd., Unit 1468, Houston, TX 77030, USA. ${ }^{7}$ Rheumatology and Rehabilitation

Department, Assiut University Hospitals, Faculty of Medicine, Assiut, Egypt. ${ }^{8}$ Department of General Internal Medicine, Section of Rheumatology and Clinical Immunology, The University of Texas MD Anderson Cancer Center, Houston, TX, USA. ${ }^{9}$ Department of Genitourinary Medical Oncology, The University of Texas MD Anderson Cancer Center, Houston, TX, USA.

${ }^{10}$ Department of Melanoma, The University of Texas MD Anderson Cancer Center, Houston, TX, USA.

Received: 20 September 2018 Accepted: 6 December 2018 Published online: 06 January 2019

\section{References}

1. Eggermont AM, Chiarion-Sileni V, Grob JJ, et al. Adjuvant ipilimumab versus placebo after complete resection of high-risk stage III melanoma (EORTC 18071): a randomised, double-blind, phase 3 trial. Lancet Oncol. 2015;16:522-30. 
2. Weber J, Mandala M, Del Vecchio M, et al. Adjuvant Nivolumab versus Ipilimumab in resected stage III or IV melanoma. N Engl J Med. 2017;377: 1824-35.

3. Antonia SJ, Villegas A, Daniel D, et al. Durvalumab after Chemoradiotherapy in stage III non-small-cell lung Cancer. N Engl J Med. 2017;377:1919-29.

4. Brahmer JR, Lacchetti C, Schneider BJ, et al. Management of ImmuneRelated Adverse Events in Patients Treated With Immune Checkpoint Inhibitor Therapy: American Society of Clinical Oncology Clinical Practice Guideline. J Clin Oncol. 2018. https://doi.org/10.1200/JCO.2017.77.6385.

5. Sznol M, Ferrucci PF, Hogg D, et al. Pooled analysis safety profile of Nivolumab and Ipilimumab combination therapy in patients with advanced melanoma. J Clin Oncol. 2017;35:3815-22.

6. Weber JS, Hodi FS, Wolchok JD, et al. Safety profile of Nivolumab monotherapy: a pooled analysis of patients with advanced melanoma. J Clin Oncol. 2017;35:785-92.

7. Puzanov I, Diab A, Abdallah K, et al. Managing toxicities associated with immune checkpoint inhibitors: consensus recommendations from the Society for Immunotherapy of Cancer (SITC) toxicity management working group. J Immunother Cancer. 2017;5:95.

8. Postow MA. Managing immune checkpoint-blocking antibody side effects. Am Soc Clin Oncol Educ Book. 2015:76-83. https://doi.org/10.14694/ EdBook_AM.2015.35.76

9. Jonathan T, Lin MS, Salvatore S, Shoushtari AN, Glezerman I. Membranous Nephropathy Related to the Checkpoint Inhibitor Nivolumab. J Am Soc Nephrol. 2016;27:102A.

10. Ina Cusnir KS, Yacyshyn E. Granulomatosis with Polyangitis Assosciated with Immune Checkpoint Blockade: Case report and Literature Review. J Rheumatol. 2017:950-A247

11. Fadel F, El Karoui K, Knebelmann B. Anti-CTLA4 antibody-induced lupus nephritis. N Engl J Med. 2009;361:211-2.

12. van den Brom RR, Abdulahad WH, Rutgers A, et al. Rapid granulomatosis with polyangiitis induced by immune checkpoint inhibition. Rheumatology (Oxford). 2016;55:1143-5.

13. Daanen RA, Maas RJH, Koornstra RHT, Steenbergen EJ, van Herpen CML, Willemsen A. Nivolumab-associated nephrotic syndrome in a patient with renal cell carcinoma: a case report. J Immunother. 2017:40:345-8.

14. Kitchlu A, Fingrut W, Avila-Casado C, et al. Nephrotic syndrome with Cancer immunotherapies: a report of 2 cases. Am J Kidney Dis. 2017;70:581-5.

15. Kishi S, Minato M, Saijo A, et al. A case of IgA nephropathy after nivolumab therapy for postoperative recurrence of lung squamous cell carcinoma. Intern Med. 2018;57(9):1259-63.

16. Jung K, Zeng X, Bilusic M. Nivolumab-associated acute glomerulonephritis: a case report and literature review. BMC Nephrol. 2016;17:188.

17. Mehta RL, Kellum JA, Shah SV, et al. Acute kidney injury network: report of an initiative to improve outcomes in acute kidney injury. Crit Care. 2007;11:R31.

18. Cortazar FB, Marrone KA, Troxell ML, et al. Clinicopathological features of acute kidney injury associated with immune checkpoint inhibitors. Kidney Int. 2016:90:638-47.

19. Jha V, Ganguli A, Saha TK, et al. A randomized, controlled trial of steroids and cyclophosphamide in adults with nephrotic syndrome caused by idiopathic membranous nephropathy. J Am Soc Nephrol. 2007;18:1899-904.

20. Nochaiwong S, Ruengorn C, Awiphan R, et al. The association between proton pump inhibitor use and the risk of adverse kidney outcomes: a systematic review and meta-analysis. Nephrol Dial Transplant. 2018;33: 331-42.

21. Wanchoo R, Karam S, Uppal NN, et al. Adverse renal effects of immune checkpoint inhibitors: a narrative review. Am J Nephrol. 2017;45:160-9.

22. Shirali AC, Perazella MA, Gettinger S. Association of Acute Interstitial Nephritis with Programmed Cell Death 1 inhibitor therapy in lung Cancer patients. Am J Kidney Dis. 2016;68:287-91.

23. Murakami N, Borges TJ, Yamashita M, Riella LV. Severe acute interstitial nephritis after combination immune-checkpoint inhibitor therapy for metastatic melanoma. Clin Kidney J. 2016:9:411-7.

24. Francisco LM, Sage PT, Sharpe AH. The PD-1 pathway in tolerance and autoimmunity. Immunol Rev. 2010;236:219-42.

25. Postow MA, Sidlow R, Hellmann MD. Immune-related adverse events associated with immune checkpoint blockade. N Engl J Med. 2018; 378:158-68

26. Cohen Tervaert JW, Ye C, Yacyshyn E. Adverse events associated with immune checkpoint blockade. N Engl J Med. 2018;378:1164-5.
27. Michot JM, Bigenwald C, Champiat S, et al. Immune-related adverse events with immune checkpoint blockade: a comprehensive review. Eur J Cancer. 2016;54:139-48

28. Friedman CF, Proverbs-Singh TA, Postow MA. Treatment of the immunerelated adverse effects of immune checkpoint inhibitors: a review. JAMA Oncol. 2016:2:1346-53.
Ready to submit your research? Choose BMC and benefit from:

- fast, convenient online submission

- thorough peer review by experienced researchers in your field

- rapid publication on acceptance

- support for research data, including large and complex data types

- gold Open Access which fosters wider collaboration and increased citations

- maximum visibility for your research: over $100 \mathrm{M}$ website views per year

At $\mathrm{BMC}$, research is always in progress.

Learn more biomedcentral.com/submissions 